Check for updates

Cite this: RSC Adv., 2021, 11, 4574

Received 12th November 2020 Accepted 5th January 2021

DOI: $10.1039 / \mathrm{d} 0 \mathrm{ra0} 0640 \mathrm{~g}$

rsc.li/rsc-advances

\section{lodonium salts as efficient iodine(III)-based noncovalent organocatalysts for Knorr-type reactions $\uparrow$}

\author{
Sevilya N. Yunusova, ${ }^{a}$ Alexander S. Novikov, (D) ${ }^{a}$ Natalia S. Soldatova, ${ }^{a}$ \\ Mikhail A. Vovk (D ${ }^{b}$ and Dmitrii S. Bolotin (D) *a
}

Hypervalent iodine(III)-derivatives display higher catalytic activity than other aliphatic and aromatic iodine(I)or bromine(I)-containing substrates for a Knorr-type reaction of $\mathrm{N}$-acetyl hydrazides with acetyl acetone to give $\mathrm{N}$-acyl pyrazoles. The highest activity was observed for dibenziodolium triflate, for which $10 \mathrm{~mol} \%$ resulted in the generation of $\mathrm{N}$-acyl pyrazole from acyl hydrazide and acetyl acetone typically at $50{ }^{\circ} \mathrm{C}$ for $3.5-6 \mathrm{~h}$ with up to $99 \%$ isolated yields. ${ }^{1} \mathrm{H}$ NMR titration data and DFT calculations indicate that the catalytic activity of the iodine(III) is caused by the binding with a ketone.

\section{Introduction}

In the past decade, organocatalysis has been the focus of extensive studies owing to its significant advantages over catalysis by metal-containing species including lower toxicity, reduced environmental footprint, and low to negligible sensitivity to air and moisture. ${ }^{\mathbf{1 , 2}}$ In general, these organocatalysts can function either through a covalent or noncovalent bonding activation. A covalent activation mode involves the formation of covalent bond(s) between a substrate and catalyst (such as amines, ${ }^{\mathbf{1 - 5}}$ heterocyclic carbenes, ${ }^{\mathbf{1 , 6}, 7}$ or phosphines $^{8}$ ), whereas a noncovalent mode involves the activation of substrates through noncovalent linkages to the catalyst.,9-18

For noncovalent catalysis, an organic catalyst typically interacts with a substrate through hydrogen bonding (HB), and many important results were achieved for the reactions based on such HB donors as ureas, ${ }^{2,19-24}$ squaramides, ${ }^{24-26}$ and other Brønsted acids, ${ }^{27-31}$ whereas catalytic reactions involving halogen $(\mathrm{XB})^{\mathbf{9 , 1 0 , 1 5 , 3 2 - 3 5}}$ or chalcogen bonding $(\mathrm{ChB})^{\mathbf{3 4 , 3 6 , 3 7}}$ are far less explored. Although XB has been established as a valuable tool in solid-state chemistry and crystal engineering, ${ }^{38-41}$ over the last five years XB has been studied in solution ${ }^{33-35,42-44}$ and applied to homogeneous catalytic transformations. ${ }^{\mathbf{9 , 1 5 , 1 6 , 3 4 , 3 7}}$

Recently Huber and coworkers reported that iodine(III) derivatives such as diaryliodonium salts can serve as efficient organocatalysts and utilize XBs for which the catalytic activity is similar or even higher than other well-proven organocatalysts

${ }^{a}$ Institute of Chemistry, Saint Petersburg State University, Universitetskaya Nab. 7/9, Saint Petersburg, 199034, Russian Federation. E-mail: d.s.bolotin@spbu.ru ${ }^{b}$ Center for Magnetic Resonance, Saint Petersburg State University, Universitetskii Pr., 26, Saint Petersburg, 198504, Russian Federation

$\dagger$ Electronic supplementary information (ESI) available. See DOI: 10.1039/d0ra09640g that are based on iodine(I) derivatives, such as oligodentate 2iodoimidazolium species. ${ }^{45,46}$ Indeed, diaryliodonium salts exhibited a high catalytic activity in reactions in which a halide abstraction occurred ${ }^{46}$ (including their application in living cationic polymerization of olefins; ${ }^{47}$ Fig. 1 (i) and (ii)) and in the synthetic transformations of carbonyl compounds, namely

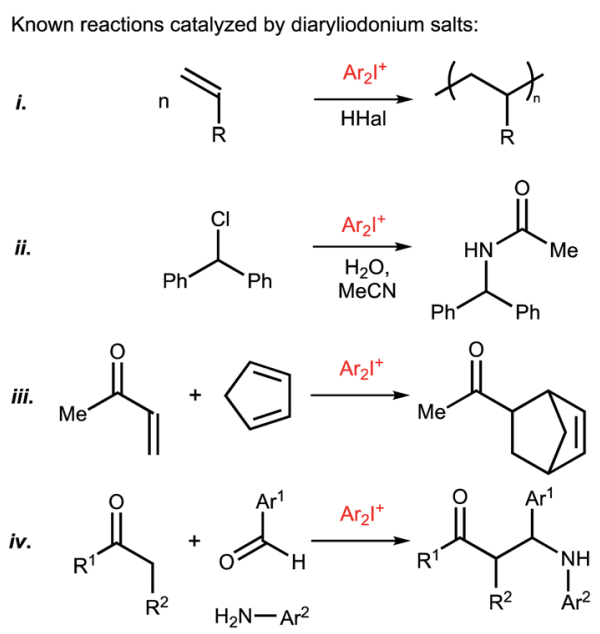

Suggested modes of activation:
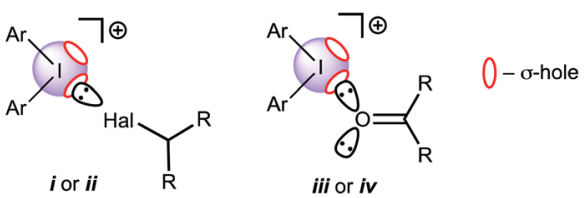

Fig. 1 Previously studied reactions catalyzed by diaryliodonium salts and plausible modes of activation of substrates. $\sigma$-hole is a region of positive electrostatic potential on an atom. ${ }^{49}$ 
Diels-Alder cycloaddition $^{46}$ (Fig. 1(iii)) and Mannich reaction ${ }^{48}$ (Fig. 1(iv)).

Considering the promising catalytic properties of diaryliodonium salts and the small number of reported examples for their application in homogeneous organocatalysis, further studies are worthwhile. In this study, we report on the catalytic activity of a series of diaryliodonium salts and provide a comparison of their activity with other XB donors in a model reaction that requires carbonyl activation. In agreement with previous suggestions that the catalytic activity of diaryliodonium salts is caused by the electrophilic activation of the electrophile, ${ }^{46,47}$ their catalytic activity in the studied Knorr-type cyclization is caused by binding with a ketone.

\section{Results and discussion}

Knorr-type syntheses ${ }^{50,51}$ conventionally proceed under mild conditions even in the absence of a catalyst if amines and carbonyl compounds are employed as the reactants. ${ }^{52}$ However, for less nucleophilic hydrazine derivatives, e.g. 2-pyridine hydrazines $^{50}$ or acyl hydrazides, ${ }^{53,54}$ a catalyst is desirable to conduct the reaction under mild conditions. Thus, the reaction of $N$-acyl hydrazides with 1,3-dicarbonyl compounds, which leads to $N$-acyl pyrazoles, typically requires an additional activation and is usually conducted in the presence of a Brønsted or a Lewis acid under reflux for several hours. ${ }^{55-57}$ This reaction was chosen as a model to verify the catalytic effect of diaryliodonium salts.

\section{Comparison of the catalytic activity for the halogen- containing organic species}

Benzoyl hydrazide (BH) was treated with acetyl acetone (AA) in $\mathrm{CD}_{3} \mathrm{OD}\left(50{ }^{\circ} \mathrm{C}, 5 \mathrm{~h}\right)$, which led to only a trace amount of the corresponding $N$-benzoyl pyrazole 1 (Fig. 2 and Table 1, entry 1 ). The addition of 1 equivalent (equiv.) of iodine(I)- or bromine(I)containing species A-E, which feature expressed $\sigma$-holes at their halogen atoms, ${ }^{58-60}$ resulted in negligible or no catalytic effect (entries 1-6). In contrast, the utilization of the dibenziodolium species $\mathbf{F}, \mathbf{G}$, and $\mathbf{H}$ led to a significant acceleration and a halfconversion was achieved after approximately $70 \mathrm{~min}$ (entries 79). Notably, other types of iodine(III) species (I and J) appeared to be catalytically inactive in the model reaction (entries 10-11) and the results obtained for the activity of $\mathbf{F}-\mathbf{I}$ are fully consistent with the recently reported relative Lewis acidity of the iodine(III)-based XB donors. ${ }^{61}$

Having examined dibenziodolium triflate $\mathbf{H}$, whose catalytic activity was the highest among all the studied halogencontaining species, we further optimized the reaction conditions. Based upon ${ }^{1} \mathrm{H}$ NMR monitoring of the reaction performed with various relative quantities of AA, we found that the optimal quantity of the carbonyl reactant was 1.2 equiv. (Fig. 3; Table 1, entries 9, 12, 13).

The S-shape of the kinetic curves was caused by the initial accumulation of the intermediate $\mathrm{MeC}(=\mathrm{NNHBz}) \mathrm{CH}_{2} \mathrm{COMe}$ in the reaction mixture, which was then transformed to 1 . The overlap of the proton resonances of $\mathrm{MeC}(=\mathrm{NNHBz}) \mathrm{CH}_{2} \mathrm{COMe}$ with those of the reactants and with the signals of 1 did not

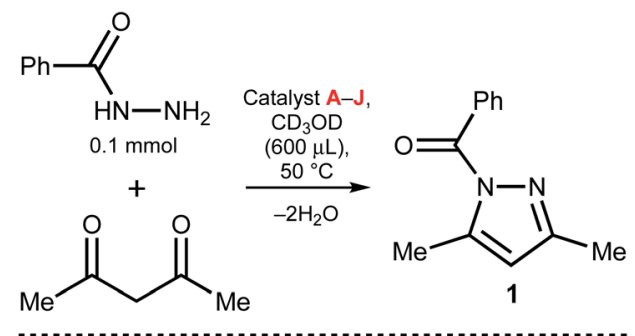<smiles>BrC(Br)(Br)Br</smiles>

A<smiles>Fc1c(F)c(F)c(Br)c(F)c1F</smiles><smiles>[X]CCCCCC</smiles><smiles>CCC(C)(C)C(C)(C)C</smiles>

I<smiles>Brc1ccccc1</smiles>

B<smiles>Fc1c(F)c(F)c(I)c(F)c1F</smiles>

$X=$ TFA $F$ $\mathrm{NTf}_{2} \mathrm{G}$<smiles>C[Y]1[IH]OC(=O)c2ccccc21</smiles><smiles>Ic1ccccc1</smiles>

C
Fig. 2 Halogen-containing species tested as organocatalysts.

Table 1 Comparison of the catalytic activity of various halogencontaining species

\begin{tabular}{llllll}
\hline Entry & Catalyst & $\begin{array}{l}\text { Catalyst load } \\
(\mathrm{mol} \%)\end{array}$ & $\begin{array}{l}\text { AA } \\
\text { load (equiv.) }\end{array}$ & $\begin{array}{l}t \\
(\mathrm{~min})\end{array}$ & Yield (\%) \\
\hline 1 & None & - & 1 & 300 & Traces \\
2 & $\mathbf{A}$ & 100 & 1 & 300 & 32 \\
3 & $\mathbf{B}$ & 100 & 1 & 300 & Traces \\
4 & $\mathbf{C}$ & 100 & 1 & 300 & Traces \\
5 & $\mathbf{D}$ & 100 & 1 & 300 & 30 \\
6 & $\mathbf{E}$ & 100 & 1 & 300 & 29 \\
7 & $\mathbf{F}$ & 100 & 1 & 70 & 50 \\
8 & $\mathbf{G}$ & 100 & 1 & 70 & 46 \\
$\mathbf{9}$ & $\mathbf{H}$ & $\mathbf{1 0 0}$ & $\mathbf{1}$ & 70 & $\mathbf{5 2}$ \\
10 & $\mathbf{I}$ & 100 & 1 & 70 & 3 \\
11 & $\mathbf{J}$ & 100 & 1 & 70 & Traces \\
12 & $\mathbf{H}$ & 100 & 1.5 & 70 & 98 \\
13 & $\mathbf{H}$ & 100 & 1.2 & 70 & 95 \\
14 & $\mathbf{H}$ & 50 & 1.2 & 100 & 98 \\
15 & $\mathbf{H}$ & 10 & 1.2 & 220 & 98
\end{tabular}




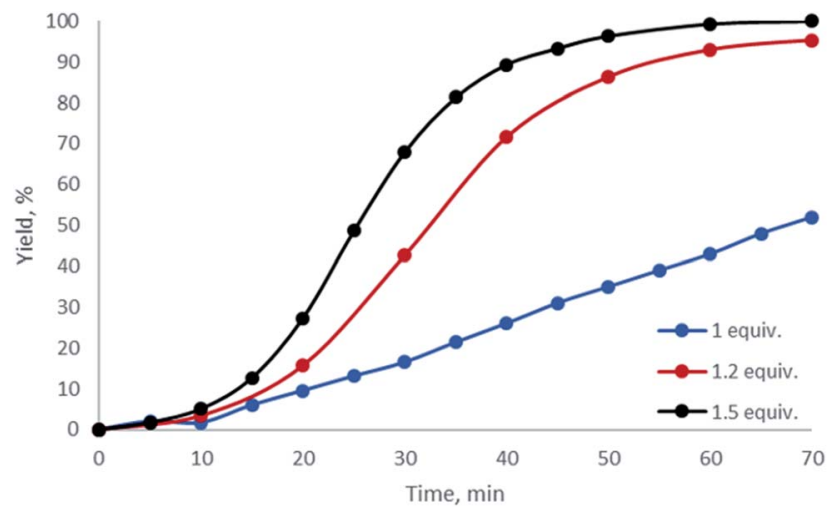

Fig. $3{ }^{1} \mathrm{H}$ NMR monitoring of the reaction of benzoyl hydrazide with various amounts of acetylacetone in the presence of 1 equiv. $\mathrm{H}$ in $\mathrm{CD}_{3} \mathrm{OD}$ at $50^{\circ} \mathrm{C}$ (entries $9,12,13$ ). NMR yield of 1 is given on the $y$-axis.

allow the accurate calculation of its relative concentration; therefore, the corresponding plot is not provided.

Next, the relative quantity of organocatalyst $\mathbf{H}$ was varied (Fig. 4, Table 1, entries 1, 9, 14, 15) and we found that even $10 \mathrm{~mol} \%$ of $\mathbf{H}$ effectively catalyzed the reaction and $\mathbf{1}$ could be obtained within $1 \mathrm{~d}$ (Table 1, entry 15).

The optimal conditions for the studied reaction were $10 \mathrm{~mol} \%$ of $\mathbf{H}, 1.2$ equiv. of the 1,3-dicarbonyl component, and $50{ }^{\circ} \mathrm{C}$. Under these conditions the substrate scope was verified.

\section{Binding of $\mathbf{H}$ with the reaction substrates}

(i) ${ }^{1} \mathbf{H}$ NMR titration. To confirm the binding of $\mathbf{H}$ with the reactants, we performed a ${ }^{1} \mathrm{H}$ NMR titration. In these experiments, $\mathbf{B H}$ or $\mathbf{A A}(2,4,6,8$, or 10 equiv.) were added to 1 equiv. of $\mathbf{H}$ in a $\mathrm{CD}_{3} \mathrm{CN}$ solution $(0.038 \mathrm{M})$. The titration by $\mathbf{B H}$ (Fig. 5) indicated a high-field shift (approx. $0.5 \mathrm{ppm}$ ) of the 2-, 3-, and 4$\mathrm{H}$ resonances, whereas the $1-\mathrm{H}$ resonances of $\mathrm{H}$ atoms located in close proximity to the I atom indicated a low-field shift by approximately $0.5 \mathrm{ppm}$ (Fig. 6). Based upon the changes in the chemical shift of the $1-\mathbf{H}$ protons, the $\mathbf{H} \cdot \mathbf{B H}$ binding constant was estimated as 2.8(2) $\mathrm{L} \mathrm{mol}^{-1}$. The opposite shift of the $1-\mathrm{H}$ protons might indicate the binding of $\mathbf{H}$ with benzyl hydrazide in solution through $\mathrm{XB}$ as this would allow the ligated

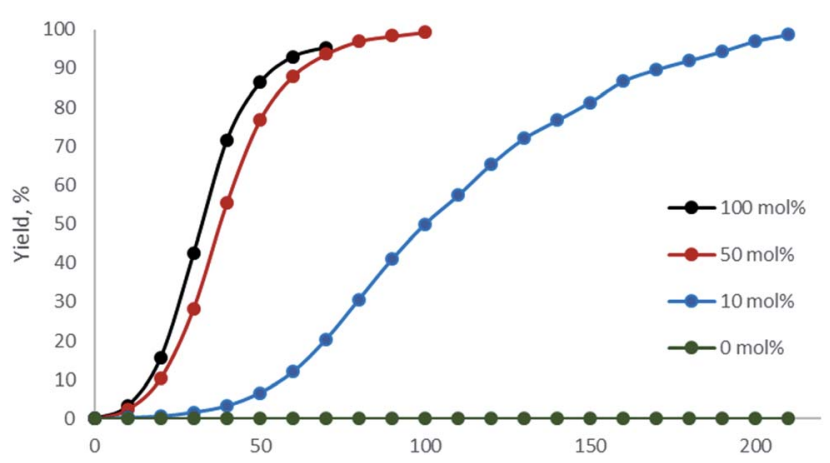

Fig. $4{ }^{1} \mathrm{H}$ NMR monitoring of the reaction of benzoyl hydrazide with acetylacetone with variable amount of $\mathrm{H}\left(\mathrm{CD}_{3} \mathrm{OD}, 50{ }^{\circ} \mathrm{C}\right.$; entries 1,9 , 14, 15).<smiles>[12H]c1ccc(C(=O)N([B])N)c([18OH])c1</smiles>

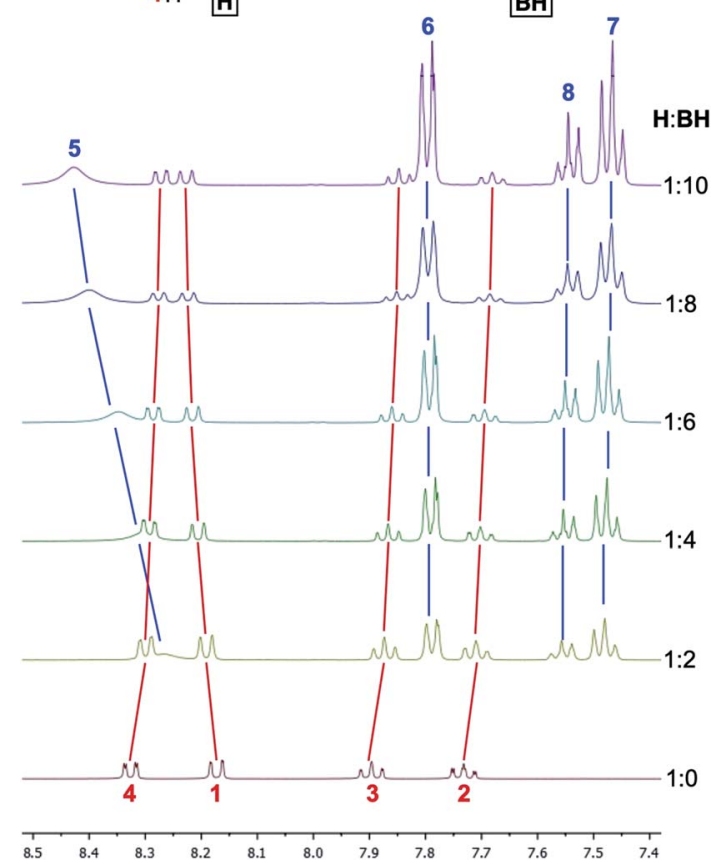

Fig. 5 The ${ }^{1} \mathrm{H}$ NMR titration of $\mathrm{H}$ by benzoyl hydrazide.

nucleophile to directly interact with the atoms while the other $\mathrm{H}$ atoms remain intact.

The titration of $\mathbf{H}$ by $\mathbf{A A}$ resulted in negligible changes in the chemical shifts (within $0.002 \mathrm{ppm}$ ) for the dibenziodolium cation, even with an excess of AA up to 25-fold; therefore, the corresponding binding constant could not be estimated. This observation might indicate either a low value of the binding constant or similar chemical shifts of the $\mathrm{H}$ atoms in the $\mathbf{H}-\mathbf{A A}$ complex and separated substrates $\mathbf{H}$ and $\mathbf{A A}$.

(ii) DFT calculations. Based on the ${ }^{1} \mathrm{H}$ NMR titration data, we performed DFT calculations to clarify the binding of $\mathbf{H}$ with $\mathbf{B H}$ and $\mathbf{A A}$ in a $\mathbf{M e O H}$ solution. Initial calculations indicated that

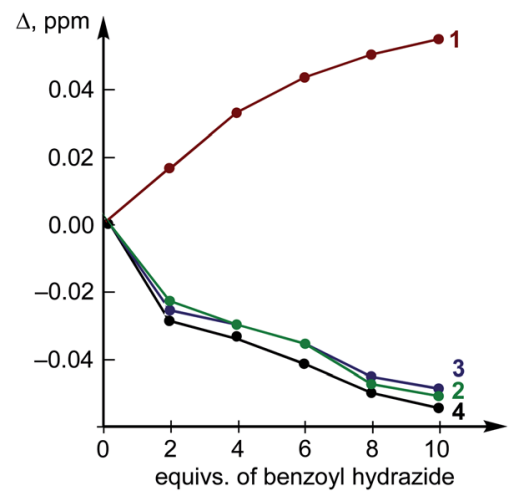

Fig. 6 The changes in chemical shifts of the $\mathrm{H}$ proton resonances upon the titration. 
Table 2 The calculated Gibbs free energy $(\Delta G)$ and enthalpy change $(\Delta H)$ for direct binding of $\mathrm{H}$ with the substrates in $\mathrm{MeOH}$ solution ${ }^{a}$

\begin{tabular}{llll}
\hline Entry & Reaction & $\begin{array}{l}\Delta G \\
\left(\mathrm{~kJ} \mathrm{~mol}^{-1}\right)\end{array}$ & $\begin{array}{l}\Delta H \\
(\mathrm{~kJ} \mathrm{~mol})\end{array}$ \\
\hline 1 & $\mathbf{H}+\mathbf{B H} \rightarrow \mathbf{H} \cdot \mathbf{B H}$ (binding by O) & 25.5 & -20.9 \\
2 & $\mathbf{H}+\mathbf{B H} \rightarrow \mathbf{H} \cdot \mathbf{B H}$ (binding by N) & 24.7 & -25.1 \\
3 & $\mathbf{H}+\mathbf{A A} \rightarrow \mathbf{H} \cdot \mathbf{A A}$ & 28.0 & -27.2 \\
4 & i & -1.3 & 23.8 \\
5 & ii & 1.7 & 22.2 \\
6 & iii & 1.3 & 18.0
\end{tabular}

${ }^{a} \mathbf{H}$ - dibenziodolium triflate; BH - benzoyl hydrazide; AA - acetyl acetone.

the direct coupling of the reagents is thermodynamically unfavorable in terms of the Gibbs free energy, which conflicts with the experimentally observed titration data at least for $\mathbf{B H}$ (Table 2, entries 1-3).

Considering that the enthalpies of all the reactions are negative, these results indicate the significant impact of entropy change in the model systems. Accordingly, we included $\mathrm{MeOH}$ solvent molecules, which are the subject of substitution during the binding of the substrates, in the explicit form in the model systems (Scheme 1).

The obtained results (Table 2, entries 4-6) appeared to be coherent with the titration data, i.e. the experimentally observed small negative $\Delta G$ for the binding of BH (approx. $-2.5(5) \mathrm{kJ} \mathrm{mol}^{-1}$ within 3 st. dev. based on $K=2.8(2) \mathrm{L} \mathrm{mol}^{-1}$ at $298 \mathrm{~K}$ ) and the absence AA binding. Moreover, the theoretical calculations indicated that the binding of the $\mathrm{O}$ atom in $\mathbf{B H}$ to the I atom in $\mathbf{H}$ is more energetically favorable in $\mathrm{MeOH}$ than coordination by the $\mathrm{N}^{\mathrm{sp}^{3}}$ atom.

\section{Theoretical study of the catalytic mechanism}

To understand the catalytic mechanism of $\mathbf{H}$ in the studied reaction $\left(\mathbf{B H}+\mathbf{A A} \rightarrow \mathbf{1}+2 \mathrm{H}_{2} \mathrm{O}\right)$, DFT calculations were performed for the first (and apparently rate-limiting) step. Initial calculations indicated that the direct nucleophilic attack of the $\mathrm{N}^{\mathrm{sp} 3}$ atom in $\mathbf{B H}$ on the $\mathrm{C}$ atom in the carbonyl moiety of AA was impossible in the absence of $\mathbf{H}$. All attempts to fix on the potential energy surface of the zwitterionic intermediate $\mathrm{PhC}(=$ O) $\mathrm{NHN}^{+} \mathrm{H}_{2} \mathrm{C}\left(-\mathrm{O}^{-}\right) \mathrm{MeCH}_{2} \mathrm{COMe}$ and the corresponding transition state (TS) for a nucleophilic attack were unsuccessful in the absence of bound $\mathbf{H}$ (the geometry optimization procedure resulted in the collapse of the relevant model structures to the initial reactants). Nevertheless, the zwitterionic intermediate formation is possible then $\mathbf{H}$ is bound to AA (Scheme 2, a-c; accordingly to the processes on Scheme 1, an additional four $\mathrm{MeOH}$ solvent molecules were taken into account in the explicit form).

For the proton transfer from the $\mathrm{N}$ atom to the $\mathrm{O}$ atom, the inclusion of one $\mathrm{MeOH}$ solvent molecule in the reaction mechanism was realized (TS2, TS3, and TS4) ${ }^{62}$ Incorporation of the solvent molecule in the transition state of the rate-limiting reaction step was successfully employed by us in previous theoretical studies. ${ }^{63}$ For aprotic solvents, at least in the case of
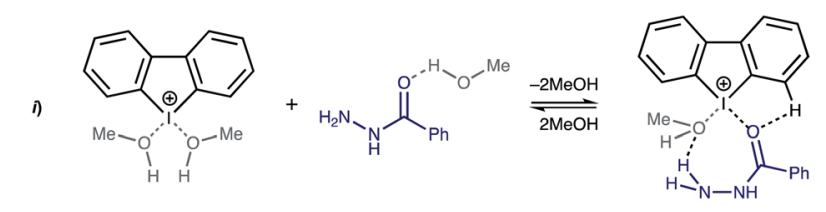

ii)
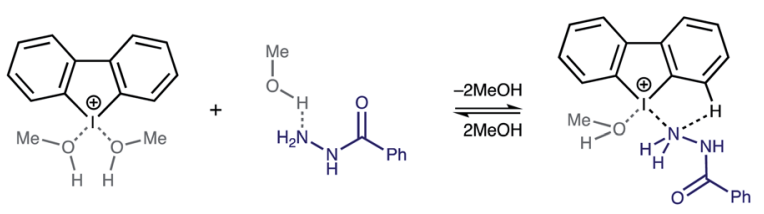

iii)
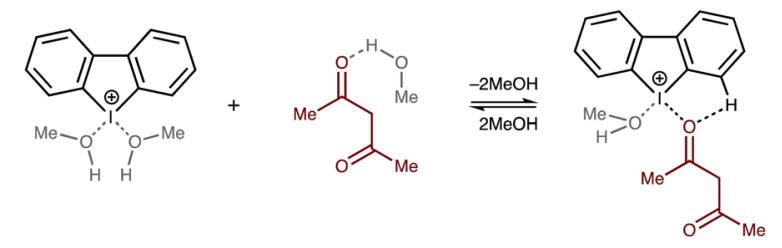

Scheme 1 Model binding reactions.

hydrazine derivatives, an additional molecule of a protic solvent can be changed by a second molecule of the nucleophile. ${ }^{53}$

Next, three reaction paths for the proton transfer were studied, i.e., the catalyzed route provided by the coupling of $\mathbf{H}$ with AA (C to D via TS2), the non-catalyzed route (G to E via TS3), and the coupling of $\mathbf{H}$ with the $\mathbf{B H}$ (G to $\mathbf{H}$ via TS4). The binding of $\mathbf{H}$ with an electrophilic substrate (AA) resulted in stabilization of the zwitterionic intermediate and reduced the Gibbs free energy of activation for the reaction (Fig. 7, TS2). The binding of $\mathbf{H}$ with $\mathbf{B H}$ (acting in this reaction as a nucleophile) resulted in a decrease in the energy of the transition state TS4 in compare with TS2 and TS3, but taking into account that cyclic intermediate I was not found, this reaction path was ruled out.

Based on the kinetic measurements, ${ }^{1} \mathrm{H}$ NMR titration data, and DFT calculations, the plausible mechanism of the studied reaction includes the binding of the organocatalyst $\mathbf{H}$ with $\mathbf{A A}$ (Scheme 2, a), a nucleophilic attack of the $\mathrm{N}^{\mathrm{sp}^{3}}$ atom on the $\mathrm{C}$ atom of the carbonyl group of $\mathbf{A A}$ (b and $\mathrm{c}$ ), incorporation of a $\mathrm{MeOH}$ solvent molecule for the proton transfer ( $\mathrm{d}$ and e), and regeneration of $\mathbf{H}$ (f).

To better understand how organocatalyst $\mathbf{H}$ binds with the reaction substrates, a theoretical estimation of the strength of the hydrogen and halogen bonds in the optimized equilibrium model structures was performed using the topological analysis of the electron density distribution technique (QTAIM analysis, see Table $1 \mathrm{~S}$ in ESI for details $\dagger$ ). The calculations indicated that in all the structures, $\mathbf{H}$ forms typical noncovalent bonds with ligands and the bond energies of $\mathrm{H} \cdots \mathrm{O}$ and $\mathrm{I} \cdots \mathrm{O}$ are 9.2$15.8 \mathrm{~kJ} \mathrm{~mol}^{-1}$ and $19.6-35.7 \mathrm{~kJ} \mathrm{~mol}^{-1}$, respectively.

\section{Investigation of covalent catalysis by $\mathbf{H}$}

Another type of catalysis-through the formation of covalent bonds of the $\mathrm{O}$ atom of the AA carbonyl moiety-was also checked theoretically. All attempts to fix on the potential energy surface of the different kinds of minima for the Meisenheimer complex-like intermediates were unsuccessful (Fig. 8). Thus, 


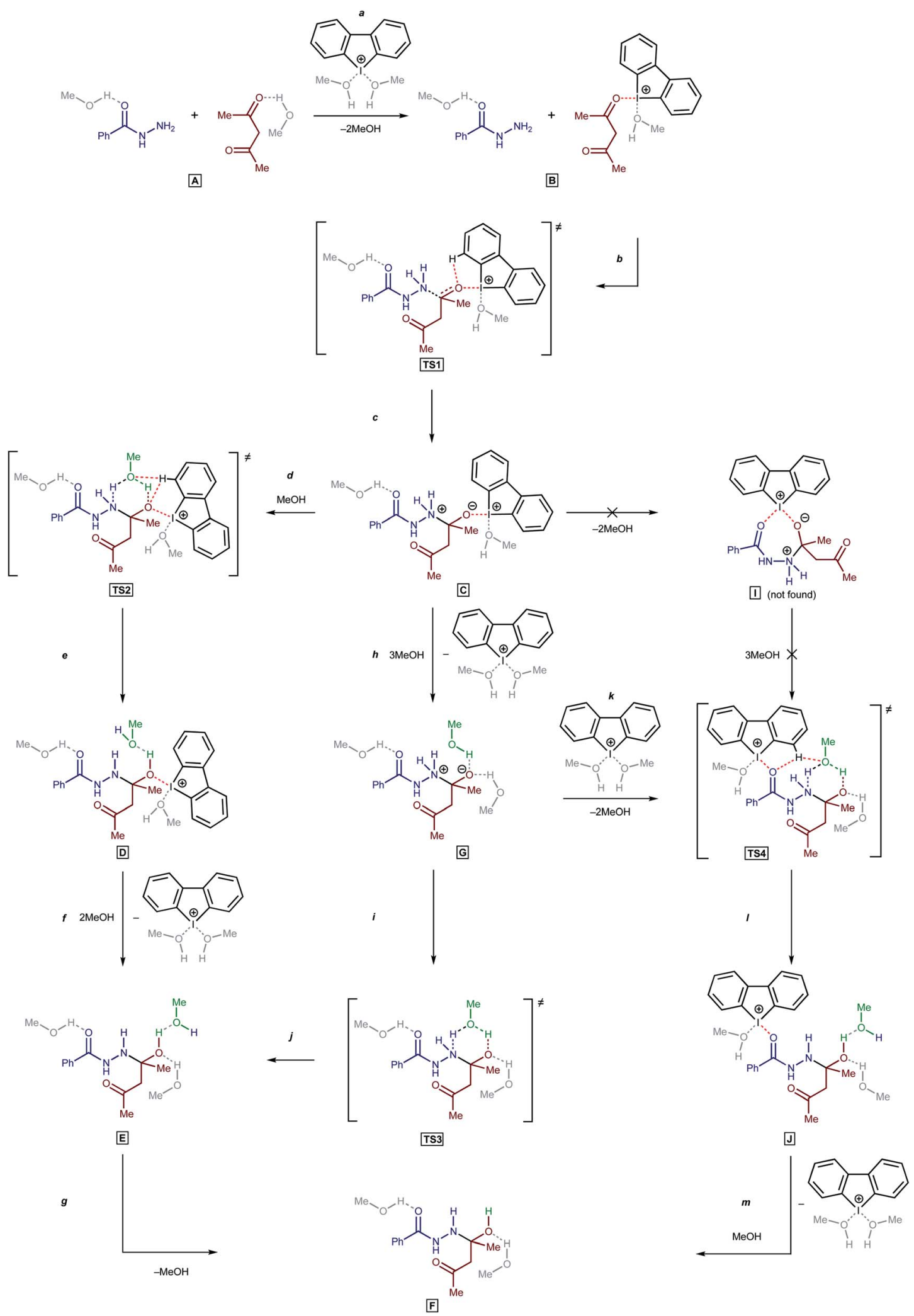

Scheme 2 Possible reaction paths. 


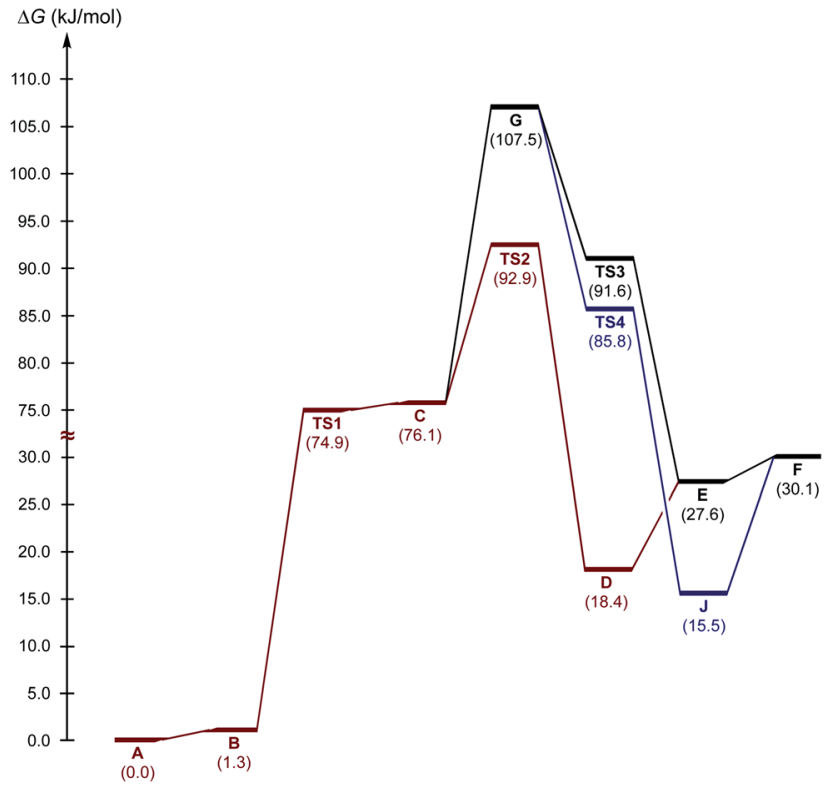

Fig. 7 The energy profile for the studied reaction paths.

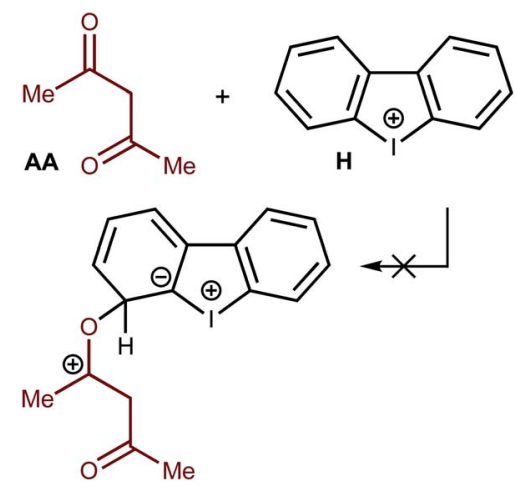

Fig. 8 One of the five hypothetical Meisenheimer complex-like intermediate.

geometry optimization for the appropriate model species obtained through the formation of O-C-I, O-C-H1, O-C-H2, O-C$\mathrm{H} 3$, and $\mathrm{O}-\mathrm{C}-\mathrm{H} 4$ (accordingly to the numeration on Fig. 4) led to the initial reactants, and these hypothetical structures were excluded from consideration. These results excluded the possibility of covalent catalysis.

\section{Reaction scope}

Dibenzidolium triflate catalyzes the generation of $\mathrm{N}$-acyl pyrazoles from AA and a series of aromatic and aliphatic acyl hydrazides (Scheme 3). For the aromatic acyl hydrazides, the reaction typically proceeded for $3.5 \mathrm{~h}$, but for the substrates featuring strong EWG $\mathrm{NO}_{2}$ functionality (5) or bulky $R_{\mathrm{S}}$ in the ortho-position $(6,7,10)$ heating for $6 \mathrm{~h}$ was required. The reaction with the aliphatic acyl hydrazides also required a prolonged reaction time (12-15). In all studied cases, the reactions initially were monitored by ${ }^{1} \mathrm{H}$ NMR and each reaction was stopped when the concentration of 1-15 was maximal, rather

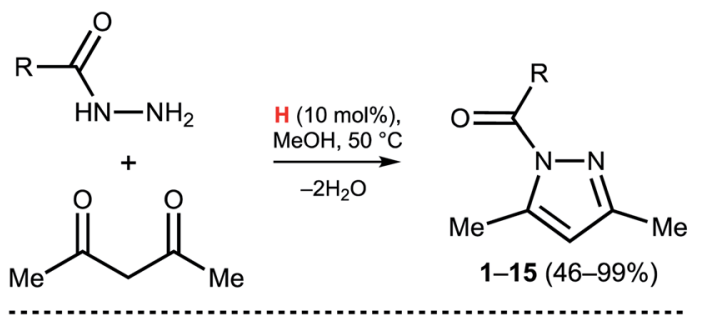

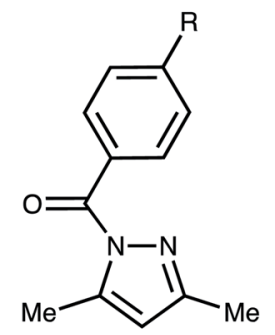

1, $\mathrm{R}=\mathrm{H}, 99 \%(3.5 \mathrm{~h})$

2, $\mathrm{R}=\mathrm{OEt}, 95 \%(3.5 \mathrm{~h})$

$3, \mathrm{R}=\mathrm{Me}, 99 \%(3.5 \mathrm{~h})$

4, $\mathrm{R}=\mathrm{Cl}, 84 \%(3.5 \mathrm{~h})$

$5, \mathrm{R}=\mathrm{NO}_{2}, 46 \%(6 \mathrm{~h})$

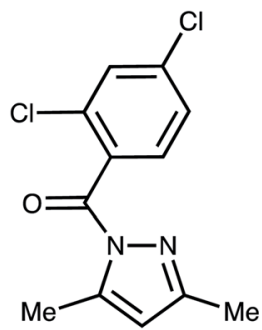

$11,78 \%(3.5 \mathrm{~h})$

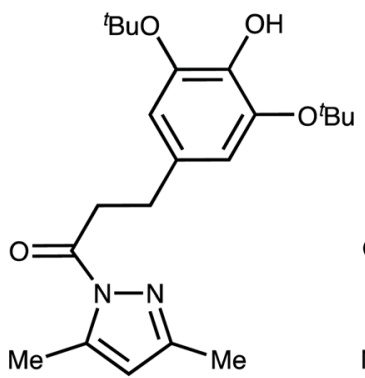

$13,52 \%(6 h)$

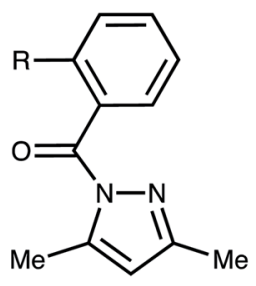

6, $\mathrm{R}=\mathrm{NH}_{2}, 67 \%(6 \mathrm{~h})$

7, $\mathrm{R}=1$-pyrrolyl, $74 \%(6 \mathrm{~h})$

8, $\mathrm{R}=\mathrm{Me}, 90 \%(3.5 \mathrm{~h})$

9, $\mathrm{R}=\mathrm{Cl}, 70 \%(3.5 \mathrm{~h})$

$10, \mathrm{R}=\mathrm{CF}_{3}, 75 \%(6 \mathrm{~h})$

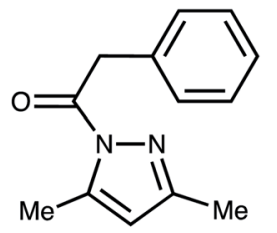

$12,60 \%(6 h)$

$14,60 \%(6 h)$

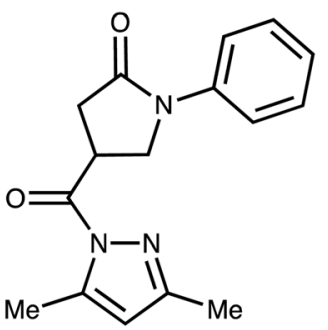<smiles>Cc1nn(C(=O)CSc2nc3ccccc3s2)c(C)c1C(C)(C)C</smiles>

Scheme 3 Substrate scope. Isolated yields are given.

than at the maximal conversion. This is caused by the slow solvolysis of 1-15 under the reaction conditions to give 3,5dimethyl pyrazole and the corresponding $\mathrm{RCO}_{2} \mathrm{Me}$. Our experiments indicated that isolation of the products after $24 \mathrm{~h}$ 
resulted in reduced yields of the pyrazoles by approximately $25 \%$ (except 15: isolated yield 53\% after $24 \mathrm{~h}$ ).

\section{Conclusions}

We found that dibenziodolium salts are convenient iodine(III)based noncovalent organocatalysts, which effectively catalyze the Knorr-type reactions of $N$-acetyl hydrazides with AA to give $N$-acyl pyrazoles. The reactivity of these salts only slightly depends on the identity of the cation, but, as expected, ${ }^{61}$ the reactivity of the triflate appears to be higher than the other studied salts. ${ }^{1} \mathrm{H}$ NMR titration data and DFT calculations provided collateral evidence that in $\mathrm{MeOH}$, the catalyst binds to the hydrazide species, which serve as a nucleophile, and this binding proceeds through halogen and hydrogen bonds. Our study indicates that for correct study of binding of iodonium salts with substrates, solvent molecules should be taken into account in the explicit form.

The catalytic effect of the iodonium salt is caused by binding with the ketone, which is less energetically favorable than binding with the hydrazide. Binding to the electrophile results in the reduction of the Gibbs free energy of the transition state of a rate-limiting step of the reaction and thus causes the catalytic effect of the iodonium salt.

\section{Experimental section}

\section{Materials and instrumentation}

Solvents and acetylacetone were obtained from commercial sources and used as received. Acyl hydrazides ${ }^{64}$ and iodine(III) derivatives ${ }^{65-67}$ were synthesized by the known methods. All syntheses were conducted in air. Chromatographic separation was carried out on Macherey-Nagel silica gel 60 M (0.063-0.2 $\mathrm{mm})$. Analytical TLC was performed on unmodified Merck ready-to-use plates (TLC silica gel 60 F254) with UV detection. Melting points were measured on a Stuart SMP30 apparatus in capillaries and are not corrected. Electrospray ionization massspectra were obtained on a Bruker micrOTOF spectrometer equipped with an electrospray ionization (ESI) source. The instrument was operated in positive ion mode using an $\mathrm{m} / \mathrm{z}$ range 50-1200. The nebulizer gas flow was 1.0 bar and the drying gas flow 4.0 L $\mathrm{min}^{-1}$. For $\mathrm{HRESI}^{+}$, the studied compounds were dissolved in MeOH. ${ }^{1} \mathrm{H},{ }^{13} \mathrm{C}\left\{{ }^{1} \mathrm{H}\right\}$ and ${ }^{19} \mathrm{~F}$ NMR spectra were measured on a Bruker Avance 400 in $\mathrm{CD}_{3} \mathrm{CN}$, $\left(\mathrm{CD}_{3}\right)_{2} \mathrm{SO}$, or $\mathrm{CD}_{3} \mathrm{OD}$ at $298 \mathrm{~K}$; the residual solvent signal was used as the internal standard.

\section{Preparation procedure for benzoyl hydrazide}

A heterogeneous mixture of methyl benzoate (341 mg, 250 $\mathrm{mmol})$ and hydrazine monohydrate $(15.0 \mathrm{~g}, 300 \mathrm{mmol})$ was refluxed for $18 \mathrm{~h}$ during which time a clear colorless solution was obtained. After cooling, all volatile components were evaporated in vacuo, and the resulting colorless crystalline solid was dried at room temperature. Recrystallization from benzene/ ethanol (5:1) gave analytically pure benzohydrazide as colorless needles (27.1 g, 79\%).

\section{Preparation procedure for $F$}

2-Iodobiphenyl (0.898 mmol, $251.0 \mathrm{mg})$ and TFA (1.39 mL) were dissolved in $\mathrm{CH}_{2} \mathrm{Cl}_{2}(5 \mathrm{~mL})$ and $\mathrm{CH}_{2} \mathrm{Cl}_{2}$ was added until a volume of $10 \mathrm{~mL}$ was reached. Then the reagent mixture was pumped through an Oxone filled column with a syringe pump (flow rate of $0.11 \mathrm{~mL} \mathrm{~min}{ }^{-1}$ ). After the addition of the reagent, the syringe was immediately replaced with a syringe containing $\mathrm{CH}_{2} \mathrm{Cl}_{2}(10 \mathrm{~mL}) . \mathrm{CH}_{2} \mathrm{Cl}_{2}$ was pumped for $30 \mathrm{~min}$ (flow rate of $\left.0.11 \mathrm{~mL} \min ^{-1}\right)$ and then the flow rate was increased (0.5 $\mathrm{mL} \min ^{-1}$ ) until no $\mathrm{CH}_{2} \mathrm{Cl}_{2}$ was left in the syringe. The solvent was removed from the resulting solution in vacuo and the obtained residue was diluted with water $(5 \mathrm{~mL})$. The product was extracted with $\mathrm{CH}_{2} \mathrm{Cl}_{2}(3 \times 5 \mathrm{~mL})$. The organic layer was dried over $\mathrm{Na}_{2} \mathrm{SO}_{4}$ and the solvent was removed in vacuo. Then $\mathrm{Et}_{2} \mathrm{O}(5$ $\mathrm{mL}$ ) was added to the residue and formation precipitate formation was observed. The suspension was stirred for $10 \mathrm{~min}$ and the product was filtered and washed with $\mathrm{Et}_{2} \mathrm{O}(5 \mathrm{~mL})$ and hexane $(2 \times 5 \mathrm{~mL})$. The product was dried in vacuo. Dibenzoiodonium trifluoroacetate $\mathbf{F}$ ( $96 \%$ yield, $379 \mathrm{mg}$ ) was obtained as a beige crystalline solid.

\section{Preparation procedure for $\mathbf{G}$}

$m$-CPBA $(77 \%, 0.736 \mathrm{~g}, 3.2 \mathrm{mmol})$ and a solution of $\mathrm{HNTf}_{2}$ $(1.26 \mathrm{~g}, 4.5 \mathrm{mmol})$ in $\mathrm{CH}_{2} \mathrm{Cl}_{2}(5.0 \mathrm{~mL})$ were added to a stirred solution of 2-iodobiphenyl $(0.56 \mathrm{~g}, 0.35 \mathrm{~mL}, 2.0 \mathrm{mmol})$ in anhydrous $\mathrm{CH}_{2} \mathrm{Cl}_{2}(6.0 \mathrm{~mL})$. The solution was stirred for $24 \mathrm{~h}$ at room temperature, then the solvent was removed on a rotary evaporator. $\mathrm{Et}_{2} \mathrm{O}(10 \mathrm{~mL})$ was added to the remaining solid. The mixture was stirred for $20 \mathrm{~min}$, then filtered. The obtained solid was washed with $\mathrm{Et}_{2} \mathrm{O}$ three times and dried in vacuo to produce dibenziodolium bis(trifluoromethane)sulfonimide G $(0.84 \mathrm{~g}$, $75 \%$ ) as a pale-yellow solid.

\section{Preparation procedure for $\mathbf{H}$}

$m$-CPBA (77\%, $0.736 \mathrm{~g}, 3.2 \mathrm{~mol})$ and triflic acid $(0.57 \mathrm{~mL}, 6.5$ $\mathrm{mmol}$ ) were added to a stirred solution of 2-iodobiphenyl (0.56 g, $0.35 \mathrm{~mL}, 2.0 \mathrm{mmol})$ in anhydrous $\mathrm{CH}_{2} \mathrm{Cl}_{2}(6 \mathrm{~mL})$ and stirred for $1 \mathrm{~h}$ at room temperature. Then $\mathrm{CH}_{2} \mathrm{Cl}_{2}$ was removed in vacuo. $\mathrm{Et}_{2} \mathrm{O}(4 \mathrm{~mL})$ was added to the remaining solid. The mixture was stirred for $20 \mathrm{~min}$ and then filtered. The obtained solid was washed with $\mathrm{Et}_{2} \mathrm{O}$ three times and dried in vacuo to provide dibenziodolium trifluoromethanesulfonate $\mathbf{H}(0.781 \mathrm{~g}$, 91\%) as a white solid.

\section{Preparation procedure for I}

Mixture 1 was obtained by dissolving iodobenzene $(0.898 \mathrm{mmol}$, $183 \mathrm{mg}, 100 \mu \mathrm{L})$ and TFA $(1.39 \mathrm{~mL})$ to in $\mathrm{CH}_{2} \mathrm{Cl}_{2}$ to achieve a total volume of $10 \mathrm{~mL}$. Mixture 2 was obtained by dissolving 1,3,5-trimethoxybenzene $(1.037 \mathrm{mmol})$ and TFA $(2.92 \mathrm{~mL})$ in $\mathrm{CH}_{2} \mathrm{Cl}_{2}$ to achieve a total volume of $11 \mathrm{~mL}$.

Mixture 1 was pumped through an Oxone-filled cartridge

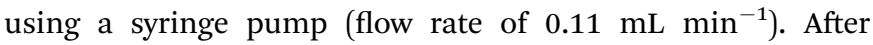
15.5 min, mixture 2 was added using a second syringe pump (flow rate of $0.11 \mathrm{~mL} \mathrm{~min}^{-1}$ ). After the addition of mixture 1 , the syringe was immediately replaced with a syringe containing 
$\mathrm{CH}_{2} \mathrm{Cl}_{2}(10 \mathrm{~mL})$ and pumped (flow rate of $0.11 \mathrm{~mL} \mathrm{~min}^{-1}$ ) until mixture 2 was completely added. Then the flow rate was increased $\left(0.22 \mathrm{~mL} \mathrm{~min}^{-1}\right)$ for $5 \mathrm{~min}$, then increased again $(0.5$ $\mathrm{mL} \min ^{-1}$ ) until the syringe was empty. The solvent was removed from the resulting solution in vacuo and the residue was diluted with water $(5 \mathrm{~mL})$. The product was extracted using $\mathrm{CH}_{2} \mathrm{Cl}_{2}(3 \times 5 \mathrm{~mL})$. The organic layer was dried over $\mathrm{Na}_{2} \mathrm{SO}_{4}$ and the solvent was removed in vacuo. Then diethyl ether $(5 \mathrm{~mL})$ was added to the residue and a precipitate was formed, the suspension was stirred for $10 \mathrm{~min}$, then the product was filtered and washed with diethyl ether $(5 \mathrm{~mL})$ and hexane $(10 \mathrm{~mL})$. The obtained product was dried in vacuo.

\section{Preparation procedure for $\mathbf{J}$}

Finely-crushed, solid 2-iodobenzoic acid (1.0 mmol) was mixed with powdered Oxone $(400 \mathrm{mg}, 0.65 \mathrm{mmol})$ in a roundbottomed flask $(50 \mathrm{~mL})$ and stirred without a solvent for 5 min using a magnetic stirrer until a homogeneous reaction mass was formed. Then the reaction mixture was cooled with ice to $5{ }^{\circ} \mathrm{C}$ and, under magnetic stirring and pre-cooled $\mathrm{H}_{2} \mathrm{SO}_{4}$ $\left(5{ }^{\circ} \mathrm{C}\right.$, total $\left.0.8 \mathrm{~mL}\right)$ was added in four portions $(0.2 \mathrm{~mL})$ to the center of the reaction mixture. After the addition of each portion, the reaction mass was mechanically shaken to achieve thorough mixing-the color of the resulting mass varied from pale yellow to brown depending on the intensity of mixing. After the addition of $\mathrm{H}_{2} \mathrm{SO}_{4}$, the reaction was continuously stirred for $30 \mathrm{~min}$ at room temperature. The mixture was then cooled to $5{ }^{\circ} \mathrm{C}, \mathrm{CH}_{2} \mathrm{Cl}_{2}(4 \mathrm{~mL})$ and 1,3,5-trimethylbenzene (3.0 $\mathrm{mmol}$ ) were added, and was then continuously stirred at room temperature for $3 \mathrm{~h}$. The reaction mixture was re-cooled to $5{ }^{\circ} \mathrm{C}$ and $\mathrm{CH}_{2} \mathrm{Cl}_{2}(5 \mathrm{~mL})$ and a saturated aqueous solution of $\mathrm{NaHCO}_{3}$ were added in small portions until pH 8.0 was reached. The organic layer was separated, and the aqueous layer was extracted with $\mathrm{CH}_{2} \mathrm{Cl}_{2}(5 \mathrm{~mL})$. The organic extracts were combined, dried with $\mathrm{Na}_{2} \mathrm{SO}_{4}$, the solvent evaporated, and the crystalline product was dried in vacuo. Additional purification of products can be performed by crystallization from water.

\section{Syntheses of 1-15}

Powder of a benzoyl hydrazide $(1.0 \mathrm{mmol})$ was added to a solution of the iodonium salt $(0.1 \mathrm{mmol})$ in methanol $(5 \mathrm{~mL})$ placed in a $10 \mathrm{~mL}$ round-bottomed flask, whereupon acetylacetone $(1.2$ mmol) was added to the mixture. The flask was closed and the obtained homogeneous solution (suspension for 12) was kept at $50{ }^{\circ} \mathrm{C}$ for $3.5 \mathrm{~h}$ (for 1-8), $6 \mathrm{~h}$ (for 9-14), or $20 \mathrm{~h}$ (for 15). For 1-15, crude product was subjected to column chromatography on silica gel (eluted with hexane : ethyl acetate $=4: 1, \mathrm{v} / \mathrm{v}$ ) and after collection of the fracture with the product the solvent was evaporated in vacuo at $50{ }^{\circ} \mathrm{C}$. A light yellow oil (1-4, 6, 8-11, and 13) and a colorless crystalline solid $(5,7,12,14$, and 15) were obtained.

Compounds 1-15 were characterized by $\mathrm{HRESI}^{+}$-MS, IR, ${ }^{1} \mathrm{H}$ and ${ }^{13} \mathrm{C}\left\{{ }^{1} \mathrm{H}\right\}$ NMR spectroscopies. $N$-Acyl pyrazoles $\mathbf{1 - 5},{ }^{\mathbf{5 4 , 6 8 - 7 1}}$ $7,^{70} 9,{ }^{54} 14,,^{72}$ and 15 (ref. ${ }^{73}$ ) were previously reported and the spectra of these species prepared by our procedure fully agree with the previously published spectral data. The ESI $\dagger$ file contains characterization and spectra of the compounds 1-15.

\section{${ }^{1}$ H NMR monitoring}

Optimization of acetylacetone amount (Fig. 3). Acetylacetone $(0.01,0.012,0.015 \mathrm{mmol})$ was added to the solution of acetyl hydrazide $(0.01 \mathrm{mmol})$ in $\mathrm{CD}_{3} \mathrm{OD}(0.3 \mathrm{~mL})$, placed in an NMR tube, whereupon catalyst $(0.001 \mathrm{mmol})$ in $\mathrm{CD}_{3} \mathrm{OD}(0.3 \mathrm{~mL})$ were added to this mixture. The NMR tube was closed and the obtained homogeneous solution was kept at $50{ }^{\circ} \mathrm{C}$ for $70 \mathrm{~min}$ in the NMR spectrometer. In this work the reaction was monitored by measuring ${ }^{1} \mathrm{H}$ NMR spectra every $10 \mathrm{~min}$ (for 0.012, $0.015 \mathrm{mmol}$ of acetylacetone) and $5 \mathrm{~min}$ (for $0.01 \mathrm{mmol}$ of acetylacetone) (4 scans, repetition time $4 \mathrm{~s}$ ) following the initial equilibration period of $5 \mathrm{~min}$. The reaction was monitored by measuring the time-dependent integral intensity of the $\mathrm{CH}_{3}$ group signal for product of reaction (1).

Optimization of the catalyst amount (Fig. 4). Acetylacetone $(0.012 \mathrm{mmol})$ was added to the solution of acetyl hydrazide $(0.01$ $\mathrm{mmol})$ in $\mathrm{CD}_{3} \mathrm{OD}(0.3 \mathrm{~mL})$, placed in an NMR tube, whereupon different amounts of $\mathbf{H}(0,0.001,0.005,0.010 \mathrm{mmol})$ in $\mathrm{CD}_{3} \mathrm{OD}$ $(0.3 \mathrm{~mL})$ were added to this mixture. The NMR tube was closed and the obtained homogeneous solution was kept at $50{ }^{\circ} \mathrm{C}$ for 70-220 min in the NMR spectrometer. In this work the reaction was monitored by measuring ${ }^{1} \mathrm{H}$ NMR spectra every $10 \mathrm{~min}(4$ scans, repetition time $4 \mathrm{~s}$ ) following the initial equilibration period of $5 \mathrm{~min}$. The reaction was monitored by measuring the time-dependent integral intensity of the $\mathrm{CH}_{3}$ group signal for the product of reaction (1).

The ${ }^{1} \mathbf{H}$ NMR titration of $\mathbf{H}$ with benzoyl hydrazide (Fig. 5 and 6). To a series of solutions of $\mathbf{H}(0.023 \mathrm{mmol})$ in $\mathrm{CD}_{3} \mathrm{CN}(0.3$ $\mathrm{mL})$ placed in an NMR tube a solution of acetyl hydrazide (0, 0.046, 0.069, 0.092, $0.115 \mathrm{mmol})$ in $\mathrm{CD}_{3} \mathrm{CN}(0.3 \mathrm{~mL})$ was added. The ${ }^{1} \mathrm{H}$ NMR spectra were measured at $298 \mathrm{~K}$.

\section{Computational details}

The full geometry optimization of all model structures in methanol solution was carried out at the DFT level of theory using the M06-2X functional ${ }^{74}$ with the help of Gaussian-09 program package. ${ }^{75}$ The quasi-relativistic pseudopotential MWB46 (ref. ${ }^{76}$ ) that described 46 core electrons and appropriate contracted basis set were used for the iodine atom and standard $6-31 G^{*}$ basis sets were used for other atoms. The solvent effects were taken into account using the SMD (Solvation Model based on Density) continuum solvation model suggested by Truhlar and coworkers. ${ }^{77}$ No symmetry restrictions have been applied during the geometry optimization procedure. The Hessian matrices were calculated analytically for all optimized model structures to prove the location of correct minimum or saddle point on the potential energy surface (no imaginary frequencies or only one imaginary frequency, respectively) and to estimate the thermodynamic parameters, the latter being calculated at $25{ }^{\circ} \mathrm{C}$. The topological analysis of the electron density distribution (QTAIM analysis $)^{78}$ was performed by using the Multiwfn program (version 3.7). ${ }^{79}$ The Cartesian atomic coordinates for all 
optimized equilibrium model structures are presented in the attached xyz-files.

\section{Conflicts of interest}

There are no conflicts to declare.

\section{Acknowledgements}

This work was supported by the Russian Science Foundation (grant 20-73-10013). Dr Pavel S. Postnikov and Prof. Dr Mekhman S. Yusubov (Tomsk Polytechnic University) are thanked for their valuable advices on the syntheses of the iodine(III) compounds conducted by N. S. S. Physicochemical studies were performed at the Center for Magnetic Resonance, Center for Xray Diffraction Studies, Chemistry Educational Centre, and Center for Chemical Analysis and Materials Research (all belonging to Saint Petersburg State University).

\section{References}

1 V. Oliveira, M. Cardoso and L. Forezi, Catalysts, 2018, 8, 605. 2 Y. Qin, L. Zhu and S. Luo, Chem. Rev., 2017, 117, 9433-9520.

3 T. Chanda and J. C. G. Zhao, Adv. Synth. Catal., 2018, 360, 279.

4 S. Vellalath and D. Romo, Angew. Chem., Int. Ed., 2016, 55, 13934-13943.

5 L. Klier, F. Tur, P. H. Poulsen and K. A. Jorgensen, Chem. Soc. Rev., 2017, 46, 1080-1102.

6 D. M. Flanigan, F. Romanov-Michailidis, N. A. White and T. Rovis, Chem. Rev., 2015, 115, 9307-9387.

7 S. Mondal, S. R. Yetra, S. Mukherjee and A. T. Biju, Acc. Chem. Res., 2019, 52, 425-436.

8 H. Guo, Y. C. Fan, Z. Sun, Y. Wu and O. Kwon, Chem. Rev., 2018, 118, 10049-10293.

9 R. Tepper and U. S. Schubert, Angew. Chem., Int. Ed., 2018, 57, 6004-6016.

10 D. Bulfield and S. M. Huber, Chem.-Eur. J., 2016, 22, 1443414450.

11 X. Zhang, J. Ren, S. M. Tan, D. Tan, R. Lee and C.-H. Tan, Science, 2019, 363, 400-404.

12 C. Bolm, A. Bruckmann and M. Pena, Synlett, 2008, 2008, 900-902.

13 S. M. Walter, F. Kniep, E. Herdtweck and S. M. Huber, Angew. Chem., Int. Ed., 2011, 50, 7187-7191.

14 F. Kniep, S. H. Jungbauer, Q. Zhang, S. M. Walter, S. Schindler, I. Schnapperelle, E. Herdtweck and S. M. Huber, Angew. Chem., Int. Ed., 2013, 52, 7028-7032.

15 R. L. Sutar and S. M. Huber, ACS Catal., 2019, 9, 9622-9639. 16 M. Breugst, D. von der Heiden and J. Schmauck, Synthesis, 2017, 49, 3224-3236.

17 C. M. Volla, I. Atodiresei and M. Rueping, Chem. Rev., 2014, 114, 2390-2431.

18 C. Thomas and B. Bibal, Green Chem., 2014, 16, 1687-1699.

19 M. N. Grayson and K. N. Houk, J. Am. Chem. Soc., 2016, 138, 9041-9044.
20 M. Puripat, R. Ramozzi, M. Hatanaka, W. Parasuk, V. Parasuk and K. Morokuma, J. Org. Chem., 2015, 80, 6959-6967.

21 N. Busschaert, C. Caltagirone, W. Van Rossom and P. A. Gale, Chem. Rev., 2015, 115, 8038-8155.

22 X. Fang and C. J. Wang, Chem. Commun., 2015, 51, 11851197.

23 O. V. Serdyuk, C. M. Heckel and S. B. Tsogoeva, Org. Biomol. Chem., 2013, 11, 7051-7071.

24 F. E. Held and S. B. Tsogoeva, Catal. Sci. Technol., 2016, 6, 645-667.

25 X. Han, H. B. Zhou and C. Dong, Chem. Rec., 2016, 16, 897906.

26 B. L. Zhao, J. H. Li and D. M. Du, Chem. Rec., 2017, 17, 9941018.

27 D. Parmar, E. Sugiono, S. Raja and M. Rueping, Chem. Rev., 2014, 114, 9047-9153.

28 T. Akiyama and K. Mori, Chem. Rev., 2015, 115, 9277-9306.

29 T. James, M. van Gemmeren and B. List, Chem. Rev., 2015, 115, 9388-9409.

30 J. Merad, C. Lalli, G. Bernadat, J. Maury and G. Masson, Chem.-Eur. J., 2018, 24, 3925-3943.

31 F. E. Held, D. Grau and S. B. Tsogoeva, Molecules, 2015, 20, 16103-16126.

32 S. Schindler and S. M. Huber, in Halogen Bonding II, ed. P. Metrangolo and G. Resnati, Springer, 2015, pp. 167-204.

33 M. Erdelyi, Chem. Soc. Rev., 2012, 41, 3547-3557.

34 S. Benz, A. I. Poblador-Bahamonde, N. Low-Ders and S. Matile, Angew. Chem., Int. Ed., 2018, 57, 5408-5412.

35 D. von der Heiden, A. Vanderkooy and M. Erdélyi, Coord. Chem. Rev., 2020, 407, 213147.

36 L. Vogel, P. Wonner and S. M. Huber, Angew. Chem., Int. Ed., 2019, 58, 1880-1891.

37 J. Bamberger, F. Ostler and O. G. Mancheno, ChemCatChem, 2019, 11, 5198-5211.

38 G. Cavallo, P. Metrangolo, R. Milani, T. Pilati, A. Priimagi, G. Resnati and G. Terraneo, Chem. Rev., 2016, 116, 24782601.

39 L. Brammer, G. Mínguez Espallargas and S. Libri, CrystEngComm, 2008, 10, 1712-1727.

40 K. Rissanen, CrystEngComm, 2008, 10, 1107-1113.

41 M. A. Kryukova, D. M. Ivanov, M. A. Kinzhalov, A. S. Novikov, A. S. Smirnov, N. A. Bokach and V. Yu Kukushkin, Chem.Eur. J., 2019, 25, 13671-13675.

42 T. M. Beale, M. G. Chudzinski, M. G. Sarwar and M. S. Taylor, Chem. Soc. Rev., 2013, 42, 1667-1680.

43 S. M. Walter, F. Kniep, L. Rout, F. P. Schmidtchen, E. Herdtweck and S. M. Huber, J. Am. Chem. Soc., 2012, 134, 8507-8512.

44 S. Libri, N. A. Jasim, R. N. Perutz and L. Brammer, J. Am. Chem. Soc., 2008, 130, 7842-7844.

45 F. Heinen, E. Engelage, C. J. Cramer and S. M. Huber, J. Am. Chem. Soc., 2020, 142, 8633-8640.

46 F. Heinen, E. Engelage, A. Dreger, R. Weiss and S. M. Huber, Angew. Chem., Int. Ed., 2018, 57, 3830-3833.

47 R. Haraguchi, T. Nishikawa, A. Kanazawa and S. Aoshima, Macromolecules, 2020, 53, 4185-4192. 
48 Y. Zhang, J. Han and Z.-J. Liu, $R S C A d v .$, 2015, 5, 2548525488.

49 T. Clark, M. Hennemann, J. S. Murray and P. Politzer, J. Mol. Model., 2007, 13, 291-296.

50 M. Nozari, A. W. Addison, G. T. Reeves, M. Zeller, J. P. Jasinski, M. Kaur, J. G. Gilbert, C. R. Hamilton, J. M. Popovitch, L. M. Wolf, L. E. Crist and N. Bastida, J. Heterocycl. Chem., 2018, 55, 1291-1307.

51 M. J. Kim, S. M. Gaube, M. H. R. Beh, C. D. Smith and A. Thompson, $R S C$ Adv., 2019, 9, 31773-31780.

52 P. G. Cozzi, Chem. Soc. Rev., 2004, 33, 410-421.

53 V. K. Burianova, D. S. Bolotin, A. S. Mikherdov, A. S. Novikov, P. P. Mokolokolo, A. Roodt, V. P. Boyarskiy, D. Dar'in, M. Krasavin, V. V. Suslonov, A. P. Zhdanov, K. Y. Zhizhin and N. T. Kuznetsov, New J. Chem., 2018, 42, 8693-8703.

54 G.-P. Yang, X. He, B. Yu and C.-W. Hu, Appl. Organomet. Chem., 2018, 32, e4532.

55 B. Balandis, G. Ivanauskaite, J. Smirnoviene, K. Kantminiene, D. Matulis, V. Mickevicius and A. Zubriene, Bioorg. Chem., 2020, 97, 103658.

56 A. Mumtaz, K. Saeed, A. Mahmood, S. Zaib, A. Saeed, J. Pelletier, J. Sevigny and J. Iqbal, Bioorg. Chem., 2020, 101, 103996.

57 L. A. Baeva, R. M. Nugumanov, R. R. Gataullin and A. A. Fatykhov, Chem. Heterocycl. Compd., 2020, 56, 548-554.

58 Z. M. Bikbaeva, D. M. Ivanov, A. S. Novikov, I. V. Ananyev, N. A. Bokach and V. Y. Kukushkin, Inorg. Chem., 2017, 56, 13562-13578.

59 K. E. Riley, J. S. Murray, J. Fanfrlik, J. Rezac, R. J. Sola, M. C. Concha, F. M. Ramos and P. Politzer, J. Mol. Model., 2011, 17, 3309-3318.

60 C. B. Aakeroy, M. Baldrighi, J. Desper, P. Metrangolo and G. Resnati, Chem.-Eur. J., 2013, 19, 16240-16247.

61 R. J. Mayer, A. R. Ofial, H. Mayr and C. Y. Legault, J. Am. Chem. Soc., 2020, 142, 5221-5233.

62 E. Erdtman, E. A. C. Bushnell, J. W. Gauld and L. A. Eriksson, Comput. Theor. Chem., 2011, 963, 479-489.

63 D. S. Bolotin, V. K. Burianova, A. S. Novikov, M. Y. Demakova, C. Pretorius, P. P. Mokolokolo, A. Roodt, N. A. Bokach, V. V. Suslonov, A. P. Zhdanov, K. Y. Zhizhin, N. T. Kuznetsov and V. Y. Kukushkin, Organometallics, 2016, 35, 3612-3623.

64 M. H. Klingele and S. Brooker, Eur. J. Org. Chem., 2004, 2004, 3422-3434.

65 P. S. Postnikov, O. A. Guselnikova, M. S. Yusubov, A. Yoshimura, V. N. Nemykin and V. V. Zhdankin, J. Org. Chem., 2015, 80, 5783-5788.
66 M. S. Yusubov, N. S. Soldatova, P. S. Postnikov, R. R. Valiev, D. Y. Svitich, R. Y. Yusubova, A. Yoshimura, T. Wirth and V. V. Zhdankin, Eur. J. Org. Chem., 2018, 2018, 640-647.

67 N. S. Soldatova, P. S. Postnikov, M. S. Yusubov and T. Wirth, Eur. J. Org. Chem., 2019, 2019, 2081-2088.

68 H. D. Mkoyi, S. O. Ojwach, I. A. Guzei and J. Darkwa, J. Organomet. Chem., 2013, 724, 95-101.

69 J. M. Ovian, C. B. Kelly, V. A. Pistritto and N. E. Leadbeater, Org. Lett., 2017, 19, 1286-1289.

70 P. A. Channar, S. Afzal, S. A. Ejaz, A. Saeed, F. A. Larik, P. A. Mahesar, J. Lecka, J. Sevigny, M. F. Erben and J. Iqbal, Eur. J. Med. Chem., 2018, 156, 461-478.

71 H. Sharghi, J. Aboonajmi, M. Mozaffari, M. M. Doroodmand and M. Aberi, Appl. Organomet. Chem., 2017, 32, e4124.

72 V. Mickevičius and R. Vaickelioniené, Chem. Heterocycl. Compd., 2008, 44, 170-172.

73 A. Rutavicius, S. Valiulene and Z. Kuodis, Chem. Heterocycl. Compd., 1995, 31, 629-633.

74 Y. Zhao and D. G. Truhlar, Theor. Chem. Acc., 2007, 120, 215241.

75 M. J. Frisch, G. W. Trucks, H. B. Schlegel, G. E. Scuseria, M. A. Robb, J. R. Cheeseman, G. Scalmani, V. Barone, B. Mennucci, G. A. Petersson, H. Nakatsuji, M. Caricato, X. Li, H. P. Hratchian, A. F. Izmaylov, J. Bloino, G. Zheng, J. L. Sonnenberg, M. Hada, M. Ehara, K. Toyota, R. Fukuda, J. Hasegawa, M. Ishida, T. Nakajima, Y. Honda, O. Kitao, H. Nakai, T. Vreven, J. A. Montgomery Jr, J. E. Peralta, F. Ogliaro, M. Bearpark, J. J. Heyd, E. Brothers, K. N. Kudin, V. N. Staroverov, T. Keith, R. Kobayashi, J. Normand, K. Raghavachari, A. Rendell, J. C. Burant, S. S. Iyengar, J. Tomasi, M. Cossi, N. Rega, J. M. Millam, M. Klene, J. E. Knox, J. B. Cross, V. Bakken, C. Adamo, J. Jaramillo, R. Gomperts, R. E. Stratmann, O. Yazyev, A. J. Austin, R. Cammi, C. Pomelli, J. W. Ochterski, R. L. Martin, K. Morokuma, V. G. Zakrzewski, G. A. Voth, P. Salvador, J. J. Dannenberg, S. Dapprich, A. D. Daniels, O. Farkas, J. B. Foresman, J. V. Ortiz, J. Cioslowski and D. J. Fox, Gaussian 09, Revision C.01, Gaussian, Inc., Wallingford CT, 2010.

76 A. Bergner, M. Dolg, W. Küchle, H. Stoll and H. Preuß, Mol. Phys., 2006, 80, 1431-1441.

77 A. V. Marenich, C. J. Cramer and D. G. Truhlar, J. Phys. Chem. B, 2009, 113, 6378-6396.

78 R. F. W. Bader, Chem. Rev., 1991, 91, 893-928.

79 T. Lu and F. Chen, J. Comput. Chem., 2012, 33, 580-592. 